\title{
Dysregulation of Group 3 Innate Lymphoid Cells in the Pathogenesis of Inflammatory Bowel Disease
}

\author{
Marianne Forkel $^{1}$ • Jenny Mjösberg ${ }^{1}$ \\ Published online: 19 September 2016 \\ (C) The Author(s) 2016. This article is published with open access at Springerlink.com
}

\begin{abstract}
Purpose of Review Here, we review recent literature indicating a role of innate lymphoid cells in human inflammatory bowel disease with a focus on the plastic population of ILC3. Recent Findings Many studies suggest an involvement of ILC3 in human intestinal inflammation. ILC3 present the most abundant ILC subtype in the human intestine at steady state. In IBD, this composition is skewed towards ILCs showing an ILC1 phenotype and cytokine profile. This change is likely due to the microenvironment causing skewing of the functionally plastic ILC subsets. Interactions between ILCs and other cells are important to keep homeostasis and intestinal barrier integrity.

Summary The knowledge about the involvement of ILCs in IBD is rapidly increasing, and with the help of mouse models, new pathways and functions of ILCs are continuously unraveled. In the majority of human studies, a potential role for ILCs in Crohn's disease is found. However, less data is available for a possible role in ulcerative colitis. Results from mice are obtained from diverse model systems, and more research in this field is needed to clarify and integrate the current knowledge in order to improve treatment strategies for IBD patients.
\end{abstract}

This article is part of the Topical Collection on Immune Deficiency and Dysregulation

\section{Jenny Mjösberg}

jenny.mjosberg@ki.se

1 Center for Infectious Medicine, Department of Medicine Huddinge, Karolinska Institutet, Stockholm, Sweden
Keywords Innate lymphoid cells $\cdot$ ILC3 $\cdot$ Inflammatory bowel disease $\cdot$ Intestinal homeostasis

\section{Introduction}

Inflammatory bowel disease (IBD) is an increasing medical problem with a strongly impaired quality of life for the patients. Until today, the causes and molecular mechanism of the disease are not clear and the available treatment regimens are unsatisfying. A role for adaptive immune cells in IBD has been established, and more recently, the innate immune system has attracted attention in the context of IBD. Many studies indicate a role for innate lymphoid cells (ILCs) in the pathogenesis of IBD. In this review, we aim to summarize the latest literature on this topic and to put the available studies into a broader context, providing an interpretation of the meaning for IBD disease pathogenesis.

\section{Classification of Human Innate Lymphoid Cells}

Innate lymphoid cells (ILCs) are a recently discovered group of innate immune cells. They are detected in many organs (blood, tonsils, thymus, liver, gut, lung, skin, uterus, and bone marrow) [1] and are especially enriched in mucosal tissues of the human body. ILCs are a relatively rare cell type, comprising only about $0.1-13 \%$ of $\mathrm{CD} 45^{+}$leukocytes depending on the organ [2]. Over the last years, ILCs have been shown to play crucial roles in the control of tissue homeostasis, as effector cells in the immune responses to infections and in inflammatory conditions [3].

ILCs develop from the common lymphoid progenitor (CLP) under the influence of IL-2R $\gamma \mathrm{c}$ signaling and 
expression of the inhibitor of DNA-binding 2 (Id2) [4]. Whereas the ontogeny of ILCs in mice is becoming increasingly understood [5], the exact developmental pathways of ILCs in humans are still unclear. Commonly, ILCs are defined by a lymphoid morphology, by the absence of markers for myeloid and dendritic cells (DCs) and, in contrast to T or B cells, by the lack of recombination activating gene (RAG)dependent rearranged antigen receptors [6].

Up until now, the family of ILCs has been divided into three subgroups, group 1, 2, and 3 ILCs (ILC1, ILC2, and ILC3), based on their transcription factor and cytokine production profile (Fig. 1). This classification is reflecting the classification of $\mathrm{T}$ helper cells in the adaptive arm of the immune system. Thus, ILCs are considered the innate counterparts of Th1, Th2, and Th17/22 cells. In contrast to T helper cells, ILCs respond rapidly to cytokine stimulation in the absence of specific antigens but once activated, they display similar effector functions as the respective groups of T helper cells [7].

Human ILC1 is a heterogeneous group comprised of NK cells, intraepithelial CD127 ${ }^{-}$ILC1 [8•], and CD127 ${ }^{+}$ILC1 $[9 \bullet \bullet]$. The former two subsets may be described as the innate counterparts of $\mathrm{CD} 8^{+} \mathrm{T}$ cells as they exert cytotoxicity and are hence not referred to as "helper" types of ILC1. In contrast, $\mathrm{CD} 127^{+}$ILC1 lack effector molecules associated with cytotoxicity, such as perforin and granzyme $\mathrm{B}$, and are therefore more similar to $\mathrm{CD}^{+}$helper $\mathrm{T}$ cells. Hence, they are considered to be the innate equivalents of Th1 cells. Mouse studies have shown that intraepithelial ILC1 and conventional NK cells are different lineages, and that they are developmentally separated from helper ILCs [10••]. All ILC1 express the transcription factor T-bet whereas NK cells and intraepithelial ILC1 additionally express eomesodermin (Eomes). Commonly, ILC1 produce the signature cytokine IFN- $\gamma$ following stimulation with IL-12 and IL-18 [11]. Together, the physiological role for ILC1 seems to be immune responses to intracellular pathogens and tumors.

ILC2 were first described in mice [12-14] and later in humans $[15,16]$ as cells dependent on the transcription factors Gata-binding protein 3 (GATA3) and retinoic acid receptor (RAR)-related orphan receptor $\alpha(\mathrm{ROR} \alpha)$ for their development [17-19]. ILC2 display a type-2 cytokine profile. In response to stimulation with IL-33, IL-25, or TSLP [13, 19, 20], they produce mainly IL-13 and IL-5, but also IL-4, IL-6, IL-8, IL-9, GM-CSF and in mice, amphiregulin [14, 15, 19, 21]. In
Fig. 1 Classification of human ILCs. Human ILCs are divided into three broad subgroups called group 1, group 2, and group 3 ILCs based on the expression of transcription factors and cytokine production

\begin{tabular}{|c|c|c|c|c|}
\hline ILC Group & Stimulation & Subtypes & Production & Function \\
\hline Group 1 ILC & $\begin{array}{l}\text { IL-15 } \\
\text { IL-12 } \\
\text { IL-18 }\end{array}$ & $\begin{array}{l}\text { Eomes } \\
\text { Tbet } \\
\text { CD127- ILC1 } \\
\begin{array}{l}\text { Eomes } \\
\text { Tbet }\end{array} \\
\text { CD127+ ILC1 } \\
\text { Tbet }\end{array}$ & $\begin{array}{l}\text { IFNy } \\
\text { Perforin } \\
\text { Granzymes } \\
\qquad \text { IFNY }\end{array}$ & $\begin{array}{l}\text { Homeostasis } \\
\text { Anti-tumor immunity } \\
\text { Immune response to } \\
\text { intracellular pathogens } \\
\text { Pathogenesis } \\
\text { Intestinal inflammation }\end{array}$ \\
\hline Group 2 ILC & $\begin{array}{l}\text { IL-33 } \\
\text { IL-25 } \\
\text { TSLP } \\
\text { PGD } \\
\text { ICOSL } \\
\text { TCR } \\
\text { NKp30L } \\
\text { TL1A }\end{array}$ & $\begin{array}{l}\text { ILC2 } \\
\begin{array}{l}\text { Gata3 } \\
\text { Rora }\end{array}\end{array}$ & $\begin{array}{l}\text { IL-13 } \\
\text { IL-5 } \\
\text { IL-4 } \\
\text { IL-9 } \\
\text { Amphi- } \\
\text { regulin }\end{array}$ & $\begin{array}{l}\text { Homeostasis } \\
\text { Helminth expulsion } \\
\text { Wound healing } \\
\text { Pathogenesis } \\
\text { Allergy } \\
\text { Asthma }\end{array}$ \\
\hline Group 3 ILC & $\begin{array}{l}\text { IL-23 } \\
\text { IL-1 } \\
\text { TL1A } \\
\text { PGE }_{2} \\
\text { AHR ligand }\end{array}$ & Roryt & $\begin{array}{l}\text { LT } \beta \\
\text { TNFa } \\
\text { IL-17 } \\
\text { IL-22 } \\
\\
\text { IL-22 }\end{array}$ & $\begin{array}{l}\text { Homeostasis } \\
\text { Immune responses to } \\
\text { extracellular pathogens } \\
\text { and rotavirus } \\
\text { Intestinal barrier function } \\
\text { Pathogenesis } \\
\text { Intestinal inflammation }\end{array}$ \\
\hline
\end{tabular}


addition, they express the prostaglandin $\mathrm{D}_{2}\left(\mathrm{PGD}_{2}\right)$ receptor CRTH2 [16] and respond to $\mathrm{PGD}_{2}$ stimulation with the production of type 2 cytokines [22]. In mice, ILC2 were shown to play a role in helminth expulsion [13].

ILC3 are defined by the expression of the RAR-related orphan receptor- $\gamma \mathrm{t}(\mathrm{ROR} \gamma \mathrm{t})$ [23] and surface expression of CD117 (c-kit) [24]. They respond to stimulation with IL-23 and IL- $1 \beta$ with production of the Th17/Th22 cytokines IL17A, IL-17F, and IL-22, either alone or in combinations [23, 24]. The group of human ILC3 includes fetal lymphoid tissue inducer (LTi) cells [25] and postnatal ILC3, which can be further divided according to the expression of the activating NK cell receptor NKp44 [26]. LTi cells are critically involved in the development of lymphoid organs during embryogenesis through secretion of lymphotoxin- $\beta$ and TNF- $\alpha$. In addition, LTi cells can express IL-17A and IL-22 [25]. Postnatally, NKp $44^{+}$ILC3 are producing IL-22 but little IL-17 whereas NKp44 ${ }^{-}$cells produce IL-17 but limited amounts of IL-22 [26]. ILC3 are generally involved in the immune response to extracellular pathogens [27].

All helper ILC subsets, i.e., with the exception of NK cells and intraepithelial ILC1, are phenotypically defined by expression of the surface proteins CD161 and CD127 (IL$7 \mathrm{R} \alpha$ ) and dependence on IL-7 for their development [6].

\section{Inflammatory Bowel Disease}

Inflammatory bowel disease (IBD) includes Crohn's disease (CD) and ulcerative colitis (UC). IBD is a chronic inflammation of the gastrointestinal tract, commonly attributed to a dysregulated immune response against the intestinal bacteria in genetically susceptible individuals. In addition, environmental factors have been implicated in the onset of disease, since the disease emerges in developing nations with westernized lifestyle and industrialization. Some of these factors influencing the risk of IBD development either positively or negatively are smoking, appendectomy, diet, medications, and pollutants [28].

IBD severely reduces the quality of life for patients, with the most common symptoms being diarrhea, abdominal pain, rectal bleeding, weight loss, and fatigue. IBD patients are at increased risk of developing other chronic autoimmune disorders like psoriasis, ankylosing spondylitis, or primary sclerosing cholangitis. About $25 \%$ of patients develop other extraintestinal manifestations of IBD like arthritis, uveitis, or skin lesions $[1,29]$.

Up to now, the exact causes of IBD are not clear and there is no curative treatment available. Most conventional drug therapies, such as anti-inflammatory drugs, corticosteroids, or immuno-suppressants [30], aim at symptomatic treatment. Relatively recently, a group of new biological treatment specimen, including anti-TNF $\alpha$ antibodies, has dramatically improved the treatment options for IBD patients [31].

There are several differences observed in the type of inflammation present in UC or CD patients. Ulcerative colitis usually affects the distal colon with continuous inflammation, which is restricted to the mucosa. In contrast, Crohn's disease can affect the entire gastrointestinal tract and shows a discontinuous and transmural inflammation [29]. In terms of the immune mechanisms involved, UC is thought to be driven by a type- 2 response including increased levels of IL-13 and IL-5 in the intestine and high expression of the type- 2 driving cytokine IL-33 and its receptor ST2 [32-34]. CD, on the other hand, is considered a type- 1 driven inflammation, characterized by increased numbers of Th1 cells and high IFN- $\gamma$ levels in response to IL-12 [32, 33, 35].

The microbiota plays a crucial role in disease pathogenesis. IBD patients present with dysbiosis, changes in microbiota, including a reduced diversity of Firmicutes and Bacteroidetes [36]. A recent study on treatment-naïve pediatric $C D$ samples investigated the microbiotic changes in more detail and suggested sampling of the mucosal microbiota as a diagnostic tool for IBD [37]. In patients suffering from IBD, the intestinal epithelium shows an increased permeability, the "leaky-gut phenomenon", which permits enhanced immune responses against the commensal microbiota [29].

Until today, it is in large parts still unclear which of the observed symptoms and immunological changes in IBD are cause or consequence of the disease and more research in this field is urgently needed.

\section{ILC in Gut Homeostasis and Inflammatory Bowel Disease}

\section{ILC3 in Gut Homeostasis}

In the healthy human intestine, all currently known ILC populations are present with ILC3 constituting the majority of ILCs in the lamina propria of the ileum [9*0] whereas published data on the distribution of the ILC subsets in the healthy human colon is missing.

ILC3 are shown to be crucially involved in intestinal homeostasis (Fig. 2). Generally, ILC3 are known as producers of IL-22 and/or IL-17 in response to IL-23 and IL-1 $\beta$. IL-22 acts on non-hematopoietic cells, such as epithelial cells, and through its heterodimeric receptor, consisting of IL-22R1 plus IL-10R2, and STAT-3 signaling induces mucosal wound healing responses and epithelial cell proliferation [38, 39]. In mice, it was further shown to mediate protection against intestinal pathogenic bacteria by inducing the production of a variety of antimicrobial peptides, such as $\operatorname{RegIII} \beta, \operatorname{RegIII} \gamma$, S100A8, and S100A9, element-sequestering proteins, and mucins [40]. 


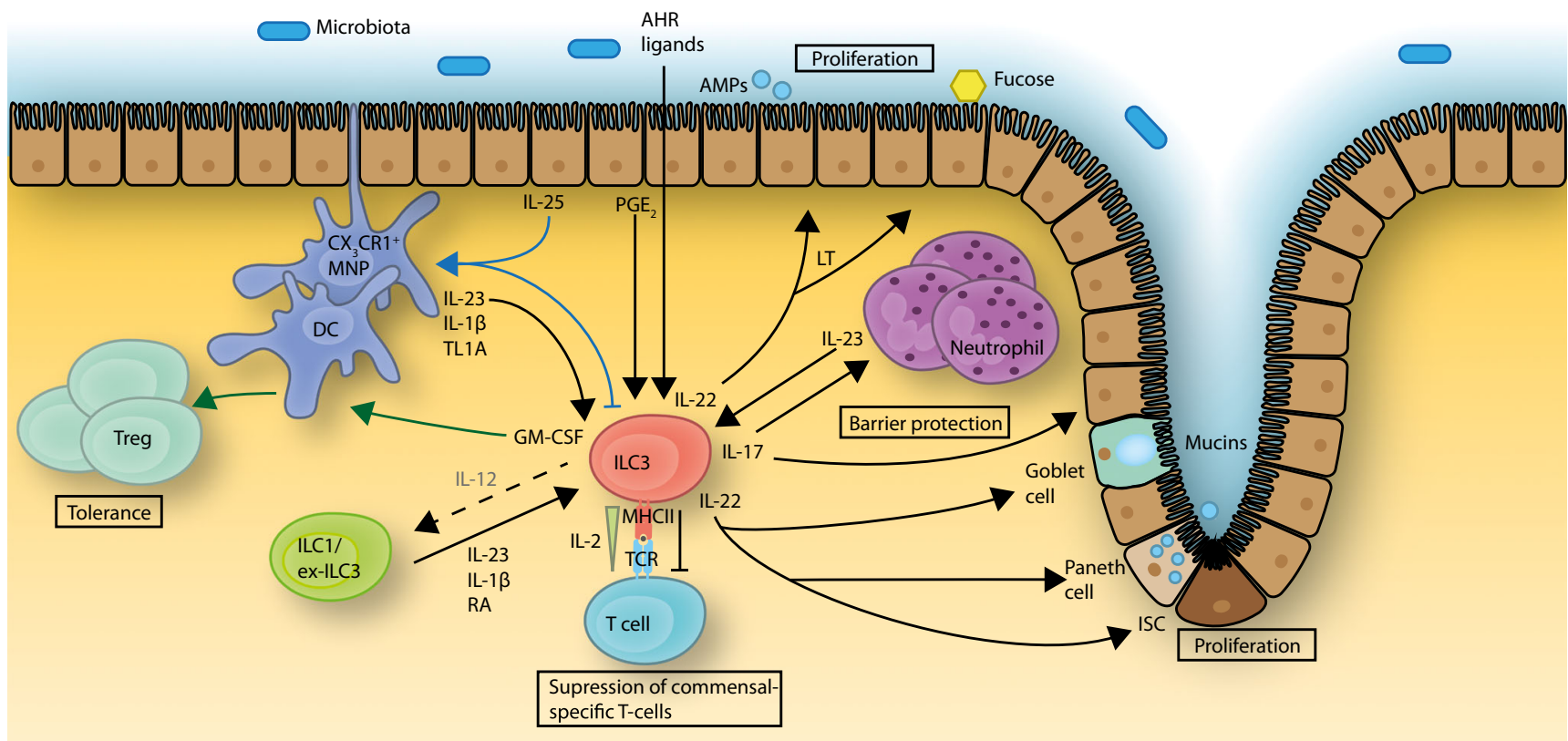

Fig. 2 ILC3 functions in gut homeostasis. ILC3 are stimulated by IL-23, IL-1 $\beta$, and TL1A, derived from MNPs and DCs to produce their signature cytokines IL-22 and IL-17 as well as GM-CSF. IL-22 promotes epithelial barrier integrity and proliferation, induces antimicrobial peptide and mucin production and, together with lymphotoxin, enhances epithelial fucosylation. IL-22 production from ILC3 can be also stimulated with epithelial cell-derived $\mathrm{PGE}_{2}$ whereas dietary AHR ligands help maintain ILC3 in the intestine. IL-17 induces

A second mechanism directly influencing the intestinal microbiota was recently described in mice. ILC3 are involved in the induction of Fut 2 in intestinal epithelial cells, an enzyme which mediates epithelial cell fucosylation [41]. This induction required commensal-dependent IL-22 and commensal-independent lymphotoxin (LT) production. Epithelial fucose is catabolized by commensal bacteria and in this way supports homeostasis of the microbiota and protection from pathogenic bacteria.

Another beneficial effector function of ILC3-derived IL-22 was observed in a mouse model of graft-versus-host disease (GVHD) and tissue damage, where IL-22 acts on intestinal stem cells to preserve the epithelial barrier integrity [42••, 43]. IL-22 production by ILC3 is enhanced through activation of the transcription factor aryl hydrocarbon receptor (AHR). AHR is a ligand-activated transcription factor with many ligands, such as tryptophan metabolites, occurring in the diet and environment [44]. the recruitment of neutrophils and also supports epithelial barrier protection. GM-CSF has been shown to be important in the induction of oral tolerance acting via DCs/MNPs. ILC3 were shown to inhibit commensal-specific T cells via the MHCII receptor together with a withdrawal of IL-2. Epithelial cell-derived IL-25 acts via MNPs/DCs to inhibit ILC3 functions. IL-23, IL-1 $\beta$, and RA can induce plasticity of ILC1 and ex-ILC3 towards an ILC3 phenotype, whereas IL-12 can reverse this effect under inflammatory conditions

Another ILC3-derived cytokine, IL-17, is known to induce the release of chemokines and other chemoattractants from epithelial and endothelial cells, which enhance the inflammation response through recruitment of pro-inflammatory neutrophils [45]. However, protective effects of IL-17, for example, in IBD, are also reported. One of the main inducers of IL17, IL-23, can be targeted by ustekinumab (anti-IL-12p40) for successful IBD treatment [46]. However, targeting IL-17 itself through secukinumab actually exacerbates IBD [47•]. This dichotomy was recently explained by the observation that IL-17 promotes epithelial barrier function in the absence of IL-23 [48, 49•]. Hence, IL-23 independent IL-17 production is protective, whereas IL-23 dependent IL-17 production might be deleterious, as suggested by the numerous mouse studies discussed in the next section.

How ILC3 are integrated into a complex network of intestinal immune cells is crucial for the understanding of their 
function, and therapeutic potential has only started to be unraveled. A major source of the ILC3-stimulating factors IL-23 or IL- $1 \beta$ in the human gut is $\mathrm{CX}_{3} \mathrm{CR} 1^{+}$mononuclear phagocytes (MNPs) or $\mathrm{CD} 14^{-}$dendritic cells $[50 \bullet$, 51]. Mononuclear phagocytes play an important role in the maintenance of gut homeostasis. They can directly sense commensal bacteria and subsequently stimulate ILC3 via IL- $1 \beta$, IL23, and TL1A to produce effector cytokines IL-22 and GMCSF [51]. In a feedback loop, GM-CSF is a crucial regulator of mononuclear phagocytes, which induce intestinal Treg cells [52]. In this way, the crosstalk between mononuclear phagocytes and ILC3 is important in the induction of tolerance towards commensals and dietary antigens. In mice, it was shown that ILC3 responses are indirectly down-regulated via IL-25, which is secreted by microbiota-stimulated epithelial cells and likely acts via DCs, which in turn limits ILC3 activation through a so far unknown mechanism [53].

In addition to being regulated by immune cell subsets such as DCs, ILC3 has the capacity to regulate the activity of other immune cells via direct cell-cell interactions with important implications for gut homeostasis. ILC3 were shown to regulate adaptive $\mathrm{T}$ cell responses through the expression of MHCII molecules. So far, most data are based on mouse studies and the expression pattern of MHCII molecules significantly differs between mouse and human. However, it seems likely that ILC-T cell interactions are also taking place in the human setting, since MHCII (HLA-DR) expression was detected on human intestinal ILC3 [54••] and defines a transcriptionally and functionally distinct ILC3 subset in the human tonsil [55 ${ }^{\circ}$. In the mouse, ILC3 limited commensal bacteria-specific T cell responses through MHCII-dependent interactions with $\mathrm{CD}^{+} \mathrm{T}$ cells and this effect was independent of ILC3 effector cytokines. Later, it was shown that this intestinal $\mathrm{T}$ cell selection is achieved by antigen presentation together with IL-2 cytokine withdrawal mediated by $\mathrm{MHCII}^{+}$ILC3 leading to programmed cell death of activated microbiotareactive T cells [56 ]. Furthermore, ILC3 were able to process and present antigen but lacked expression of the classical co-stimulatory molecules (CD40, CD80, CD86) [54••]. In contrast, it was shown that ILC3 isolated from mouse spleen express co-stimulatory molecules and induce $\mathrm{T}$ cell responses and proliferation [57]. These controversial observations might depend on the different microenvironments in different anatomical locations, which favor variable surface protein expression and diverse effector functions of ILC3. Nevertheless, the capacity of ILC3 to regulate $\mathrm{T}$ cell activity partly explains their dramatic importance, at least in certain mouse models, despite their relative rareness.

In summary, ILC3 deploy an array of cytokine-dependent and cell surface receptor-mediated mechanisms to exert homeostatic control of intestinal immunity.

\section{ILC3 in Inflammatory Bowel Disease}

Naturally, since a number of mouse models that mimic gut inflammation are available, a large amount of data indicating a role for ILCs in IBD is obtained from mouse studies. Nevertheless, many reports also indicate a role of ILCs in the promotion of IBD in humans (Fig. 3). However, the heterogeneity and plasticity within the group of ILC3, the different gating strategies used to identify ILC3, as well as the diversity of mouse models employed contribute to some confusion regarding the role for ILC3 in human gut inflammation.

Many genes related to ILC3 biology were identified in genome-wide association studies (GWAS) as risk loci for IBD. One key GWAS identified 163 risk loci for IBD, containing genes involved in autophagy, several genes of the IL23/IL-17 pathway, mucins and NOD2, a gene important for intracellular pathogen sensing [58]. Since human ILCs express a large number of these GWAS genes [55•], it is possible that some IBD risk genes partly mediate their penetrance by modifying ILC functions.

Indeed, a number of studies reported changes in the ILC composition and function within the lamina propria of IBD patients connected to those risk genes. These findings in humans are supported by data from different mouse models of intestinal inflammation. Two studies identified a decrease of IL-22 producing ILC3 in the intestine of Crohn's patients $[9 \cdot \bullet, 59]$. The protective effect of ILC3-derived IL-22 in gut inflammation was demonstrated in several mouse models. IL23-induced IL-22 was shown to attenuate colon inflammation induced by dextran sodium sulfate (DSS) or Citrobacter rodentium infection [60] and lack of IL-22 producing ILCs increased susceptibility to $C$. rodentium $[27,61]$. Furthermore, in the TCR $\alpha$ KO mouse model, representing a model of UC, IL-22 gene delivery improved colitis through mucin induction and goblet cell restitution [62]. However, in contrast to these protective and regenerative effects of ILC-22, Longman et al. found that colonic ILC3 from UC as well as CD patients showed an increased IL-22 production capacity [51] and a study using the anti-CD40 model of innate colitis found a pathogenic role for IL-22 [63]. Hence, ILC3-derived IL-22 has a complicated role in the intestine and cannot be easily designated as protective.

Takayama et al. and Bernink et al. showed a decrease of IL22 producing NKp $44^{+}$ILC3 in the lamina propria of CD patients [9••,59] but not UC patients [59]. One of the groups showed that the decrease of NKp $44^{+}$ILC3 was accompanied by a reciprocal increase of an IL- 23 responsive IFN- $\gamma$ producing cell population which showed an NK cell phenotype (CD3 ${ }^{-} \mathrm{CD}^{+} 6^{+} \mathrm{NKp} 44{ }^{-} \mathrm{NKp} 46^{+} \mathrm{CD}^{2} 7^{-}$RORgt $^{-}$) [59]. Bernink et al., on the other hand, identified a population of $\mathrm{CD} 127^{+} \mathrm{ILC} 1$ in humans that was found to be accumulated in the lamina propria of $\mathrm{CD}$ patients at the expense of $\mathrm{NKp} 44^{+}$ ILC3. These cells produced IFN- $\gamma$ under stimulation with IL- 


\section{Crohn's disease}

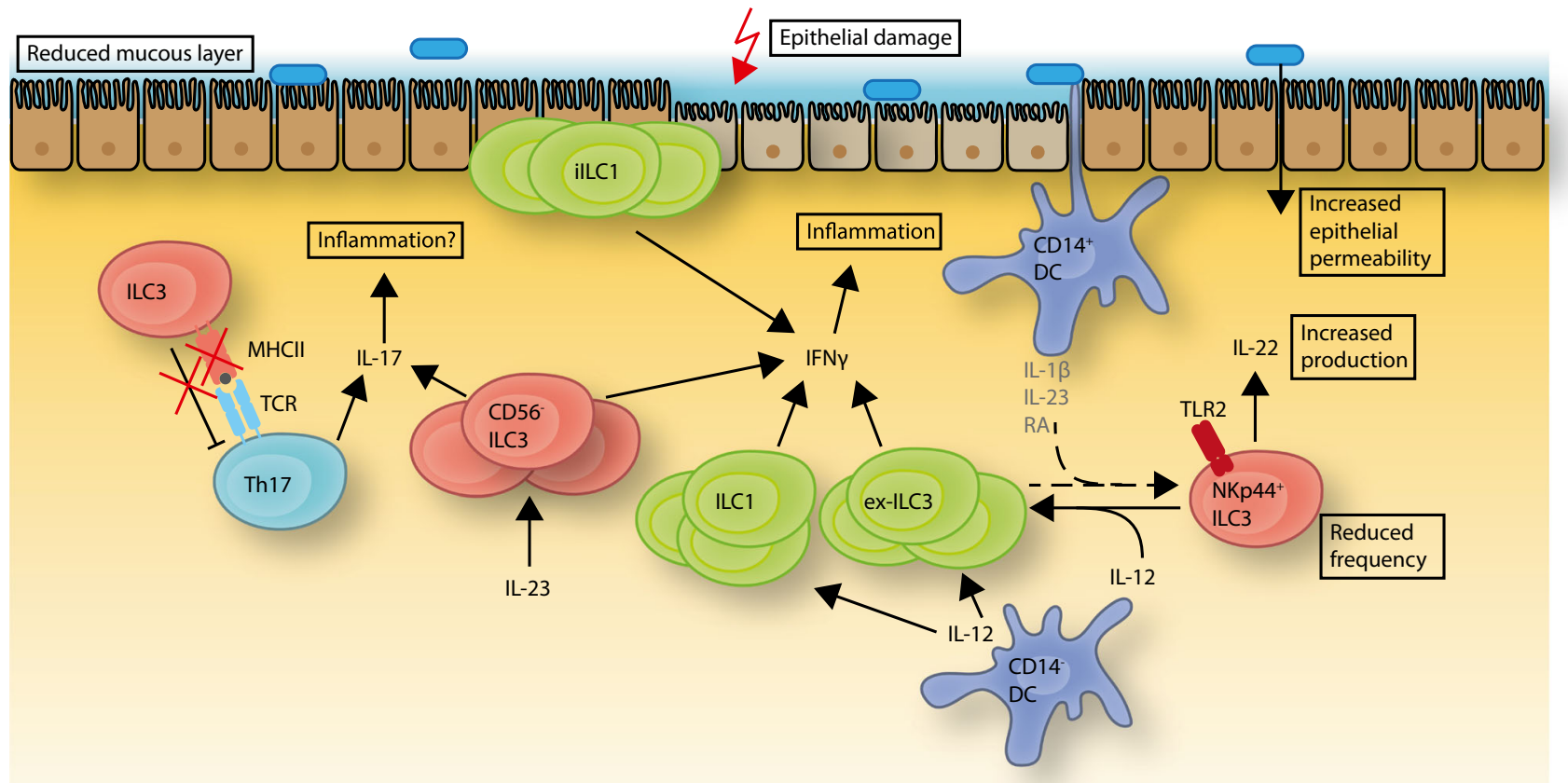

Fig. 3 Changes of ILC frequencies and functions in intestinal inflammation. In the inflamed intestine of Crohn's patients, several changes in the distribution of ILC frequencies have been observed. Homeostatic NKp44 ${ }^{+}$ILC3 are decreased whereas the frequencies of the IFN- $\gamma$-producing subsets of intraepithelial ILC1 and CD $127^{+}$ILC1 are increased. The IL-12 induced plasticity of NKp $44^{+}$ILC3 to ex-ILC3, resembling ILC1 is likely contributing to this increased frequency.

12 and were unresponsive to IL-23 or IL-1 $\beta$ [9••]. Another ILC1 subset, called intraepithelial ILC1, which resides in the intestinal epithelium and produces large amounts of IFN- $\gamma$ upon IL-12 stimulation, was also amplified in the small intestine of CD patients [8•]. These intraepithelial ILC1 were characterized by expression of CD103, NKp44, granzymes, and perforin and they expressed the transcription factors Tbet and Eomes [8•]. Hence, several studies point to an accumulation of, and a pathogenic role for, IFN- $\gamma$ producing ILCs in human gut inflammation, as shown in mice [64]. Indeed, IFN- $\gamma$ is known to promote gut inflammation by reducing tight junction integrity, enhancing leukocyte recruitment, and stimulating phagocytes [65].

Not only an increase of IFN- $\gamma$ in the intestine of IBD patients was observed but also a pro-inflammatory role for IL-17 was suggested. An increased frequency of IL-23 responsive IL-17- and IFN- $\gamma$-producing CD56 ${ }^{-}$ILC 3 in the intestine of CD patients, but not in UC patients, was detected [66], and a similar subset was found at elevated numbers in a mouse model of Helicobacter hepaticus-induced colitis [64]. In addition, a mouse model of UC in $\operatorname{Rag} 2^{-/-}$and $\mathrm{Tbet}^{-/-}$mice
Somewhat contradictory, NKp $44^{+}$ILC3 from the colon of UC and CD patients were shown to have a higher capacity for IL-22 production. An IL-17- and IFN- $\gamma$-producing CD56 subset of ILC3 was found to be increased in the intestine of Crohn's patients. In addition, the MHCII expression on intestinal ILC3 from pediatric Crohn's patients was shown to be reduced and this correlated with an increased number of Th17 cells

(TRUC mice) suggested a central role for IL-23-induced IL17 in chronic intestinal inflammation [67]. However, as mentioned above, IL-23 and IL-17 seem to have opposed, yet linked, roles where anti-IL-23 treatment improves both IBD and experimental colitis $[46,47 \bullet, 49 \bullet, 68]$, whereas anti-IL-17 treatment worsens IBD [47•].

The skewed frequencies of ILCs in the intestine of IBD patients could either be explained by specific recruitment of cells to the intestine or by plasticity between the different ILC subsets, induced by the inflammatory response. Indeed, a high degree of plasticity among ILC subsets started to be recently unraveled. Human ILC3 were shown to differentiate into IFN- $\gamma$-producing ILC1 under IL-12 stimulation. IL-12 induced down-regulation of ROR $\gamma \mathrm{t}$, up-regulation of Tbet and the cells lost the ability to produce IL-22. These ILC1-like cells are termed "ex-ILC3" [9••]. A similar conversion of ROR $\gamma \mathrm{t}^{+}$ILC3 to IFN- $\gamma$-producing ROR $\gamma \mathrm{t}^{-}$ILCs under IL12 stimulation was reported in mice [69]. Recently, IL-12 was also shown to play a role in ILC2 plasticity. An increased frequency of ILC2 in intestinal samples of Crohn's patients was found, and those cells had the ability to co-produce IL-13 
and IFN- $\gamma[70 \bullet$. In vitro ILC2 could be induced to express IFN- $\gamma$ and Tbet under the influence of IL-12. If this mechanism could play a role in the pathogenesis of UC is to date unclear, and other reports studying the involvement of ILC2 in human IBD are eagerly anticipated. IL-12 is a proinflammatory cytokine produced mainly by antigen presenting cells in response to bacterial products [71] and is present at high levels in the inflamed gut mucosa. Clinical trials with a monoclonal antibody against the shared p40 subunit of IL-12 and IL-23 could induce remission in Crohn's disease [72], but it is still unclear through which molecular mechanism improvement is achieved.

The conversion of ILC3 into ILC1 was recently shown to be reversible. $\mathrm{CD} 127^{+} \mathrm{ILC} 1$ could differentiate into ROR $\gamma \mathrm{t}^{+}$ ILC3 under stimulation with IL-2, IL-23, and IL-1 $\beta$, and this was further enhanced by retinoic acid (RA) [50••]. This reversible plasticity is an elegant mechanism through which ILCs can be instructed to adapt to the current needs in a certain microenvironment without the recruitment of cells from the circulation.

Not only a skewed profile of ILC3 effector cytokines but also altered interactions of ILC3 within the intestinal immune cell network is suggested to play a role in intestinal inflammation. ILC3 and T cell interaction seems to have a crucial function in keeping gut homeostasis. Mice with a deletion of MHCII in the ILC3 developed spontaneous intestinal inflammation in the presence of commensal bacteria with increased frequencies of pro-inflammatory (IFN- $\gamma^{+}, \mathrm{IL}_{17 \mathrm{~A}^{+}, \mathrm{TNF}} \alpha^{+}$) $\mathrm{CD}^{+} \mathrm{T}$ cells in the colon [54••]. In addition, it was found that MHCII expression on colonic ILC3 from pediatric IBD patients is reduced together with an increased frequency of Th17 cells in the colon [56•], which suggests a protective regulatory effect of MHCII expressing ILC3 in IBD.

As described above, the interaction of mononuclear phagocytes and ILC3 is important in the induction of intestinal tolerance towards commensals and dietary antigens. In the context of IBD, some studies indicate that this crosstalk could be disturbed in $\mathrm{CD}$ patients $[52,73,74]$.

Furthermore, ILC3-derived IL-22 was shown to prevent the dissemination of lymphoid-resident bacteria, specifically Alcaligenes, in mice [75]. Crohn's disease is associated with specific immune responses against Alcaligenes, which suggests a dysregulation of this mechanism in human IBD [75].

It is known that patients with inflammatory bowel disease have an increased risk of developing colorectal cancer. As described above, the IL-23 pathway is involved in intestinal inflammation in several mouse models and IL-22 has a protective effect in some models of intestinal inflammation. On the other hand, in the development of cancer, IL-22 can have a pro-tumorigenic effect. One study reported ILC3- and IL-22dependent progression of colitis-associated colorectal cancer in a mouse model [76•], which indicates the possibility of an involvement of ILC3 in human colorectal cancer. These opposing protective and pathogenic effects of IL-22 indicate that a tight regulation of this cytokine is necessary to maintain homeostasis. An important regulator of IL-22 is the DCderived IL-22 binding protein (IL-22BP). Mice lacking IL22BP showed increased incidence of tumors in an IBDassociated colorectal cancer model [77].

\section{Conclusions}

Important advances in our knowledge about immunological mechanisms in intestinal inflammation have been made, even if the initial trigger for the development of IBD is still unidentified. It is becoming increasingly clear though, that dysregulated ILCs are involved in the pathogenesis of IBD, especially through the usage of mouse models of intestinal inflammation. Different subsets of ILCs are expanded in the disease states compared to homeostasis, and more and more interactions of ILCs with other immune cells are being discovered. However, many questions concerning which of the observed alterations in ILC composition and function are causes or consequences of the inflammation are still unanswered.

Most research on humans investigating the role of ILCs in IBD focused so far on Crohn's disease, and not much data is available for ulcerative colitis. Since UC is thought of as a type 2 mediated inflammation, an interesting question is if any changes in the ILC2 compartment and their function can be observed in the disease state.

Integrating and expanding the knowledge obtained from mouse models and confirming which role ILCs play in human IBD will lead to a better understanding of intestinal immune networks and will hopefully pave the way for better and finally curative treatment of IBD.

\section{Compliance with Ethical Standards}

Conflict of Interest Dr. Mjösberg reports personal fees from ONO Pharmaceutical ltd. Dr. Forkel declares no conflicts of interest relevant to this manuscript.

Human and Animal Rights and Informed Consent This article does not contain any studies with human or animal subjects performed by any of the authors.

Open Access This article is distributed under the terms of the Creative Commons Attribution 4.0 International License (http:// creativecommons.org/licenses/by/4.0/), which permits unrestricted use, distribution, and reproduction in any medium, provided you give appropriate credit to the original author(s) and the source, provide a link to the Creative Commons license, and indicate if changes were made. 


\section{References}

Papers of particular interest, published recently, have been highlighted as:

- Of importance

•- Of major importance

1. Peters CP, Mjosberg JM, Bernink JH, Spits H. Innate lymphoid cells in inflammatory bowel diseases. Immunology letters. 2015.

2. Kim CH, Hashimoto-Hill S, Kim M. Migration and tissue tropism of innate lymphoid cells. Trends Immunol. 2016;37(1):68-79.

3. Artis D, Spits H. The biology of innate lymphoid cells. Nature. 2015;517(7534):293-301.

4. Cortez VS, Robinette ML, Colonna M. Innate lymphoid cells: new insights into function and development. Curr Opin Immunol. 2015;32:71-7.

5. Zook EC, Kee BL. Development of innate lymphoid cells. Nat Immunol. 2016;17(7):775-82.

6. Spits H, Artis D, Colonna M, Diefenbach A, Di Santo JP, Eberl G, et al. Innate lymphoid cells - a proposal for uniform nomenclature. Nat Rev Immunol. 2013;13(2):145-9.

7. Montaldo E, Juelke K, Romagnani C. Group 3 innate lymphoid cells (ILC3s): origin, differentiation, and plasticity in humans and mice. Eur J Immunol. 2015;45(8):2171-82.

8. Fuchs A, Vermi W, Lee JS, Lonardi S, Gilfillan S, Newberry RD, et al. Intraepithelial type 1 innate lymphoid cells are a unique subset of IL-12- and IL-15-responsive IFN-gamma-producing cells. Immunity. 2013;38(4):769-81. This is the first report of an intraepithelial ILC1 subset distinct from NK cells which accumulated in Crohn's disease.

9.• Bernink JH, Peters CP, Munneke M, te Velde AA, Meijer SL, Weijer K, et al. Human type 1 innate lymphoid cells accumulate in inflamed mucosal tissues. Nat Immunol. 2013;14(3):221-9. This paper shows for the first time the existence of a lamina propria ILC1 population in the human intestine which is increased in Crohn's disease. Furthermore, it demonstrates the plasticity of human ILC subsets which provides a possible mechanism for the changes observed in the inflammatory state

10.• Klose CS, Flach M, Mohle L, Rogell L, Hoyler T, Ebert K, et al. Differentiation of type 1 ILCs from a common progenitor to all helper-like innate lymphoid cell lineages. Cell. 2014;157(2):340 56. First report of the lineage-relationship between ILC populations and a bona-fide ILC1 population in mice.

11. Spits H, Bernink JH, Lanier L. NK cells and type 1 innate lymphoid cells: partners in host defense. Nat Immunol. 2016;17(7):758-64.

12. Moro K, Yamada T, Tanabe M, Takeuchi T, Ikawa T, Kawamoto H, et al. Innate production of $\mathrm{T}(\mathrm{H}) 2$ cytokines by adipose tissueassociated c-Kit(+)Sca-1(+) lymphoid cells. Nature. 2010;463(7280):540-4.

13. Neill DR, Wong SH, Bellosi A, Flynn RJ, Daly M, Langford TK, et al. Nuocytes represent a new innate effector leukocyte that mediates type-2 immunity. Nature. 2010;464(7293):1367-70.

14. Price AE, Liang HE, Sullivan BM, Reinhardt RL, Eisley CJ, Erle DJ, et al. Systemically dispersed innate IL-13-expressing cells in type 2 immunity. Proc Natl Acad Sci U S A. 2010;107(25):1148994.

15. Monticelli LA, Sonnenberg GF, Abt MC, Alenghat T, Ziegler CG, Doering TA, et al. Innate lymphoid cells promote lung-tissue homeostasis after infection with influenza virus. Nat Immunol. 2011;12(11):1045-54.

16. Mjosberg JM, Trifari S, Crellin NK, Peters CP, van Drunen CM, Piet B, et al. Human IL-25- and IL-33-responsive type 2 innate lymphoid cells are defined by expression of CRTH2 and CD161. Nat Immunol. 2011;12(11):1055-62.
17. Hoyler T, Klose CS, Souabni A, Turqueti-Neves A, Pfeifer D, Rawlins EL, et al. The transcription factor GATA-3 controls cell fate and maintenance of type 2 innate lymphoid cells. Immunity. 2012;37(4):634-48.

18. Halim TY, MacLaren A, Romanish MT, Gold MJ, McNagny KM, Takei F. Retinoic-acid-receptor-related orphan nuclear receptor alpha is required for natural helper cell development and allergic inflammation. Immunity. 2012;37(3):463-74.

19. Mjosberg J, Bernink J, Golebski K, Karrich JJ, Peters CP, Blom B, et al. The transcription factor GATA3 is essential for the function of human type 2 innate lymphoid cells. Immunity. 2012;37(4):64959

20. Halim TY, Krauss RH, Sun AC, Takei F. Lung natural helper cells are a critical source of Th2 cell-type cytokines in protease allergeninduced airway inflammation. Immunity. 2012;36(3):451-63.

21. Wilhelm C, Hirota K, Stieglitz B, Van Snick J, Tolaini M, Lahl K, et al. An IL-9 fate reporter demonstrates the induction of an innate IL-9 response in lung inflammation. Nat Immunol. 2011;12(11): 1071-7.

22. Xue L, Salimi M, Panse I, Mjosberg JM, McKenzie AN, Spits H, et al. Prostaglandin D2 activates group 2 innate lymphoid cells through chemoattractant receptor-homologous molecule expressed on TH2 cells. J Allergy Clin Immunol. 2014;133(4):1184-94.

23. Cella M, Fuchs A, Vermi W, Facchetti F, Otero K, Lennerz JK, et al. A human natural killer cell subset provides an innate source of IL22 for mucosal immunity. Nature. 2009;457(7230):722-5.

24. Crellin NK, Trifari S, Kaplan CD, Cupedo T, Spits H. Human NKp44+IL-22+ cells and LTi-like cells constitute a stable RORC+ lineage distinct from conventional natural killer cells. J Exp Med. 2010;207(2):281-90.

25. Cupedo T, Crellin NK, Papazian N, Rombouts EJ, Weijer K, Grogan JL, et al. Human fetal lymphoid tissue-inducer cells are interleukin 17-producing precursors to RORC+ $\mathrm{CD} 127+$ natural killer-like cells. Nat Immunol. 2009;10(1):66-74.

26. Hoorweg K, Peters CP, Cornelissen F, Aparicio-Domingo P, Papazian N, Kazemier G, et al. Functional differences between human NKp44(-) and NKp44(+) RORC(+) innate lymphoid cells. Front Immunol. 2012;3:72.

27. Sonnenberg GF, Monticelli LA, Elloso MM, Fouser LA, Artis D. CD4(+) lymphoid tissue-inducer cells promote innate immunity in the gut. Immunity. 2011;34(1):122-34.

28. Ng SC, Bernstein CN, Vatn MH, Lakatos PL, Loftus Jr EV, Tysk C, et al. Geographical variability and environmental risk factors in inflammatory bowel disease. Gut. 2013;62(4):630-49.

29. Abraham C, Cho JH. Inflammatory bowel disease. N Engl J Med. 2009;361(21):2066-78.

30. Danese S, Fiocchi C. Ulcerative colitis. N Engl J Med. 2011;365(18):1713-25.

31. Amiot A, Peyrin-Biroulet L. Current, new and future biological agents on the horizon for the treatment of inflammatory bowel diseases. Ther Adv Gastroenterol. 2015;8(2):66-82.

32. Heller F, Florian P, Bojarski C, Richter J, Christ M, Hillenbrand B, et al. Interleukin-13 is the key effector Th2 cytokine in ulcerative colitis that affects epithelial tight junctions, apoptosis, and cell restitution. Gastroenterology. 2005;129(2):550-64.

33. Fuss IJ, Neurath M, Boirivant M, Klein JS, de la Motte C, Strong SA, et al. Disparate CD4+ lamina propria (LP) lymphokine secretion profiles in inflammatory bowel disease. Crohn's disease LP cells manifest increased secretion of IFN-gamma, whereas ulcerative colitis LP cells manifest increased secretion of IL-5. J Immunol. 1996;157(3):1261-70.

34. Beltran CJ, Nunez LE, Diaz-Jimenez D, Farfan N, Candia E, Heine C, et al. Characterization of the novel ST2/IL-33 system in patients with inflammatory bowel disease. Inflamm Bowel Dis. 2010;16(7): 1097-107. 
35. Monteleone G, Biancone L, Marasco R, Morrone G, Marasco O, Luzza F, et al. Interleukin 12 is expressed and actively released by Crohn's disease intestinal lamina propria mononuclear cells. Gastroenterology. 1997;112(4):1169-78.

36. Frank DN, St Amand AL, Feldman RA, Boedeker EC, Harpaz N, Pace NR. Molecular-phylogenetic characterization of microbial community imbalances in human inflammatory bowel diseases. Proc Natl Acad Sci U S A. 2007;104(34):13780-5.

37. Gevers D, Kugathasan S, Denson LA, Vazquez-Baeza Y, Van Treuren W, Ren B, et al. The treatment-naive microbiome in newonset Crohn's disease. Cell Host Microbe. 2014;15(3):382-92.

38. Pickert G, Neufert C, Leppkes M, Zheng Y, Wittkopf N, Warntjen $\mathrm{M}$, et al. STAT3 links IL-22 signaling in intestinal epithelial cells to mucosal wound healing. J Exp Med. 2009;206(7):1465-72.

39. Dudakov JA, Hanash AM, van den Brink MR. Interleukin-22: immunobiology and pathology. Annu Rev Immunol. 2015;33: 747-85.

40. Zheng Y, Valdez PA, Danilenko DM, Hu Y, Sa SM, Gong Q, et al. Interleukin-22 mediates early host defense against attaching and effacing bacterial pathogens. Nat Med. 2008;14(3):282-9.

41. Goto Y, Obata T, Kunisawa J, Sato S, Ivanov II, Lamichhane A, et al. Innate lymphoid cells regulate intestinal epithelial cell glycosylation. Science. 2014;345(6202):1254009.

42.• Hanash AM, Dudakov JA, Hua G, O'Connor MH, Young LF, Singer NV, et al. Interleukin-22 protects intestinal stem cells from immune-mediated tissue damage and regulates sensitivity to graft versus host disease. Immunity. 2012;37(2):339-50. This study provides the first indication of a protective role for ILC3 on intestinal stem cells.

43. Aparicio-Domingo P, Romera-Hernandez M, Karrich JJ, Cornelissen F, Papazian N, Lindenbergh-Kortleve DJ, et al. Type 3 innate lymphoid cells maintain intestinal epithelial stem cells after tissue damage. J Exp Med. 2015;212(11):1783-91.

44. Kiss EA, Diefenbach A. Role of the aryl hydrocarbon receptor in controlling maintenance and functional programs of rorgammat(+) innate lymphoid cells and intraepithelial lymphocytes. Front Immunol. 2012;3:124.

45. Laan M, Cui ZH, Hoshino H, Lotvall J, Sjostrand M, Gruenert DC, et al. Neutrophil recruitment by human IL-17 via C-X-C chemokine release in the airways. J Immunol. 1999;162(4):2347-52.

46. Sandborn WJ, Gasink C, Gao LL, Blank MA, Johanns J, Guzzo C, et al. Ustekinumab induction and maintenance therapy in refractory Crohn's disease. N Engl J Med. 2012;367(16):1519-28.

47. Hueber W, Sands BE, Lewitzky S, Vandemeulebroecke M, Reinisch W, Higgins PD, et al. Secukinumab, a human anti-IL17A monoclonal antibody, for moderate to severe Crohn's disease: unexpected results of a randomised, double-blind placebo-controlled trial. Gut. 2012;61(12):1693-700. Crucial trial with unexpected results indicating for the first time that IL-17 could also have tissue protective effects in the human intestine.

48. Maxwell JR, Zhang Y, Brown WA, Smith CL, Byrne FR, Fiorino $\mathrm{M}$, et al. Differential roles for Interleukin-23 and Interleukin-17 in intestinal immunoregulation. Immunity. 2015;43(4):739-50.

49. Lee JS, Tato CM, Joyce-Shaikh B, Gulen MF, Cayatte C, Chen Y, et al. Interleukin-23-Independent IL-17 production regulates intestinal epithelial permeability. Immunity. 2015;43(4):727-38. This study provides a possible mechanism for the tissue-protective effect of IL-17 in the intestine.

50.• Bernink JH, Krabbendam L, Germar K, de Jong E, Gronke K, Kofoed-Nielsen M, et al. Interleukin-12 and -23 control plasticity of CD127(+) group 1 and group 3 innate lymphoid cells in the intestinal lamina propria. Immunity. 2015;43(1):146-60. In this study it is shown that ILC3-ILC1 plasticity is bidirectional and that ILC1 and ILC3 functionally adapt to the intestinal microenvironment.
51. Longman RS, Diehl GE, Victorio DA, Huh JR, Galan C, Miraldi ER, et al. CX(3)CR1(+) mononuclear phagocytes support colitisassociated innate lymphoid cell production of IL-22. J Exp Med. 2014;211(8):1571-83.

52. Mortha A, Chudnovskiy A, Hashimoto D, Bogunovic M, Spencer SP, Belkaid Y, et al. Microbiota-dependent crosstalk between macrophages and ILC3 promotes intestinal homeostasis. Science. 2014;343(6178):1249288.

53. Sawa S, Lochner M, Satoh-Takayama N, Dulauroy S, Berard M, Kleinschek M, et al. RORgammat + innate lymphoid cells regulate intestinal homeostasis by integrating negative signals from the symbiotic microbiota. Nat Immunol. 2011;12(4): $320-6$.

54.• Hepworth MR, Monticelli LA, Fung TC, Ziegler CG, Grunberg S, Sinha R, et al. Innate lymphoid cells regulate CD4+ T-cell responses to intestinal commensal bacteria. Nature. 2013;498(7452):113-7. This is a key study providing data on the interaction of ILC with cells of the adaptive immune system.

55. Bjorklund AK, Forkel M, Picelli S, Konya V, Theorell J, Friberg D, et al. The heterogeneity of human CD127(+) innate lymphoid cells revealed by single-cell RNA sequencing. Nat Immunol. 2016;17(4):451-60. This study provides the first transcriptome analysis of human ILC, providing several novel clues as to the function of these relatively unexplored cells.

56. Hepworth MR, Fung TC, Masur SH, Kelsen JR, McConnell FM, Dubrot J, et al. Immune tolerance. Group 3 innate lymphoid cells mediate intestinal selection of commensal bacteria-specific CD4(+) T cells. Science. 2015;348(6238):1031-5. This study provides the detailed mechanisms for how ILC3 controls commensal-specific Th17 cells in the intestine.

57. von Burg N, Chappaz S, Baerenwaldt A, Horvath E, Bose Dasgupta $\mathrm{S}$, Ashok D, et al. Activated group 3 innate lymphoid cells promote T-cell-mediated immune responses. Proc Natl Acad Sci U S A. 2014;111(35):12835-40.

58. Jostins L, Ripke S, Weersma RK, Duerr RH, McGovern DP, Hui $\mathrm{KY}$, et al. Host-microbe interactions have shaped the genetic architecture of inflammatory bowel disease. Nature. 2012;491(7422): $119-24$.

59. Takayama T, Kamada N, Chinen H, Okamoto S, Kitazume MT, Chang J, et al. Imbalance of NKp44(+)NKp46(-) and NKp44(-)NKp46(+) natural killer cells in the intestinal mucosa of patients with Crohn's disease. Gastroenterology. 2010;139(3):88292, 92 e1-3.

60. Mielke LA, Jones SA, Raverdeau M, Higgs R, Stefanska A, Groom JR, et al. Retinoic acid expression associates with enhanced IL-22 production by gammadelta $\mathrm{T}$ cells and innate lymphoid cells and attenuation of intestinal inflammation. J Exp Med. 2013;210(6): $1117-24$.

61. Satoh-Takayama N, Vosshenrich CA, Lesjean-Pottier S, Sawa S, Lochner M, Rattis F, et al. Microbial flora drives interleukin 22 production in intestinal $\mathrm{NKp} 46+$ cells that provide innate mucosal immune defense. Immunity. 2008;29(6):958-70.

62. Sugimoto K, Ogawa A, Mizoguchi E, Shimomura Y, Andoh A, Bhan AK, et al. IL-22 ameliorates intestinal inflammation in a mouse model of ulcerative colitis. J Clin Invest. 2008;118(2):534 44.

63. Eken A, Singh AK, Treuting PM, Oukka M. IL-23R+ innate lymphoid cells induce colitis via interleukin-22-dependent mechanism. Mucosal Immunol. 2014;7(1):143-54.

64. Buonocore S, Ahern PP, Uhlig HH, Ivanov II, Littman DR, Maloy $\mathrm{KJ}$, et al. Innate lymphoid cells drive interleukin-23-dependent innate intestinal pathology. Nature. 2010;464(7293):1371-5.

65. Boehm U, Klamp T, Groot M, Howard JC. Cellular responses to interferon-gamma. Annu Rev Immunol. 1997;15:749-95.

66. Geremia A, Arancibia-Carcamo CV, Fleming MP, Rust N, Singh B, Mortensen NJ, et al. IL-23-responsive innate lymphoid cells are 
increased in inflammatory bowel disease. J Exp Med. 2011;208(6): 1127-33.

67. Powell N, Walker AW, Stolarczyk E, Canavan JB, Gokmen MR, Marks E, et al. The transcription factor T-bet regulates intestinal inflammation mediated by interleukin-7 receptor + innate lymphoid cells. Immunity. 2012;37(4):674-84.

68. Elson CO, Cong Y, Weaver CT, Schoeb TR, McClanahan TK, Fick $\mathrm{RB}$, et al. Monoclonal anti-interleukin 23 reverses active colitis in a T cell-mediated model in mice. Gastroenterology. 2007;132(7): 2359-70.

69. Vonarbourg C, Mortha A, Bui VL, Hernandez PP, Kiss EA, Hoyler $\mathrm{T}$, et al. Regulated expression of nuclear receptor RORgammat confers distinct functional fates to NK cell receptor-expressing RORgammat(+) innate lymphocytes. Immunity. 2010;33(5):73651.

70. Lim AI, Menegatti S, Bustamante J, Le Bourhis L, Allez M, Rogge L, et al. IL-12 drives functional plasticity of human group 2 innate lymphoid cells. J Exp Med. 2016;213:569-83. This study is the first report on ILC2 plasticity towards an ILC1 phenotype and indicates a possible involvement of such cells in IBD.

71. Croxford AL, Kulig P, Becher B. IL-12-and IL-23 in health and disease. Cytokine Growth Factor Rev. 2014;25(4):415-21.
72. Simon EG, Samuel S, Ghosh S, Moran GW. Ustekinumab: a novel therapeutic option in Crohn's disease. Expert Opin Biol Ther. 2016;16(8):1065-74.

73. Han X, Uchida K, Jurickova I, Koch D, Willson T, Samson C, et al. Granulocyte-macrophage colony-stimulating factor autoantibodies in murine ileitis and progressive ileal Crohn's disease. Gastroenterology. 2009;136(4):1261-71, e1-3.

74. Goldstein JI, Kominsky DJ, Jacobson N, Bowers B, Regalia K, Austin GL, et al. Defective leukocyte GM-CSF receptor (CD116) expression and function in inflammatory bowel disease. Gastroenterology. 2011;141(1):208-16.

75. Sonnenberg GF, Monticelli LA, Alenghat T, Fung TC, Hutnick NA, Kunisawa J, et al. Innate lymphoid cells promote anatomical containment of lymphoid-resident commensal bacteria. Science. 2012;336(6086):1321-5.

76. Kirchberger S, Royston DJ, Boulard O, Thornton E, Franchini F, Szabady RL, et al. Innate lymphoid cells sustain colon cancer through production of interleukin-22 in a mouse model. J Exp Med. 2013;210(5):917-31. In this study it was shown for the first time that ILC3 might play a role in the promotion of colorectal cancer.

77. Huber S, Gagliani N, Zenewicz LA, Huber FJ, Bosurgi L, Hu B, et al. IL-22BP is regulated by the inflammasome and modulates tumorigenesis in the intestine. Nature. 2012;491(7423):259-63. 